\title{
Exam 2 Strategy
}

Richard G. Cummings, (Email: cummingr@uww.edu), University of Wisconsin, Whitewater Robert A. Gruber, (Email: gruberr@uww.edu), University of Wisconsin, Whitewater

\begin{abstract}
After students take their first exam in an accounting course, tax accounting and intermediate accounting in this case, their reactions to their test scores may be varied. This is their first major assessment of how they have performed in the class. The students in the class near the high end of the grading scale are going to be satisfied with their score. Yet the overwhelming majority of students should be thinking about how they can do better on the next exam or an "Exam 2 strategy".

This paper describes a process which allows students to develop a strategy or "action plan" for their next exam. This process provides students a way to earn bonus points while developing their communication skills and showcasing their writing skills in a convenient electronic forum. Thus students develop their own strategy and benefit by considering the collective wisdom of the top ten strategies posted on the course web site. Detailed instructions are provided below to implement an "Exam 2 strategy" assignment which provides students an action plan to better their next exam scores.
\end{abstract}

\section{INTRODUCTION}

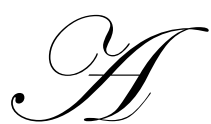

fter students take their first exam in an accounting course, tax accounting and intermediate accounting in this case, their reactions to their test scores may be varied. This is their first major assessment of how they have performed in the class. The students in the class near the high end of the grading scale are going to be satisfied with their score. Yet the overwhelming majority of students should be thinking about how they can do better on the next exam or an "Exam 2 strategy".

Cunningham (1999) states, “... the research in educational psychology suggests that most students learn more, and retain what they learn longer, when they are actively wrestling with problems and issues than when they are simply listening to a lecture (Verner and Dickinson 1967; McKeachie 1967; Bligh 1972; Costin 1972; Eble 1983; Pascarella and Terenzini 1991). For test taking strategy, we can extrapolate that students are going to be better served when they "actively wrestle" with the results of their first exam in planning for their next exam rather than being lectured about exam score improvement.

Developing a strategy for their next exam provides an opportunity for accounting students to develop their creative problem solving and written communication skills. Published position statements, white papers and research articles have indicated the need for improvement in these same skills highlighted in the expected skill set of entrylevel accountants which include interpersonal skills, oral and written communication skills, and intellectual and creative problem solving skills (Bedford 1986; Perspectives 1989; IMA 1994; AICPA 1999). Albrecht and Sack (2000) indicate that there is still a gap between theses same skills employers' expect of accounting graduates and the skills that accounting educators' provide.

This paper describes a process which allows students to develop a strategy or "action plan" for their next exam. This process provides students a way to earn bonus points while developing their communication skills and showcasing their writing skills in a convenient electronic forum. Thus students develop their own strategy and benefit by considering the collective wisdom of the top ten strategies posted on the course web site. Detailed instructions are provided below to implement an "Exam 2 strategy" assignment which provides students an action plan to better their next exam scores. 


\section{EXAM 2 STRATEGY ASSIGNMENT}

\section{Exam 1 Debriefing}

Use of multiple choice questions provides an opportunity for the questions to be machine graded and distributed to students by e-mail from your campus testing center within hours of taking the exam. Their e-mail feedback will include how many questions they answered correctly along with the item number of the questions they missed. In addition they will get their score for the exam. Since the instructor usually gets the class feedback, it is important to post a message on your course website about the exam and if you anticipate any "unofficial curve" (the curve can be made official after you have met with the class to debrief the exam). This can ameliorate many concerned e-mails.

One way to use class time is to return the exams and project a transparency key on the overhead. On a onepage transparency (a 5 x 10 table works well) you can show the test item number, the correct answer, and a source code. B, N, H, C can be a source code that indicates whether the question came from B-book, N-notes, H-homework problem,

C-class discussion or a combination of sources. This along with the student's e-mail test feedback allows the student to grade their own exam and ask any questions about the exam. An invitation to the students to continue the discussion during office hours can provide a reluctant student a venue for help.

A good debriefing process can really help with starting a developmental problem solving perspective for the student. Once the student starts to see that there may be questions from certain sources or computational or conceptual questions that were challenging on the exam the need for an action plan emerges. Now is the time to tell the students about setting up their action plan and providing a follow-up handout with the specifics.

\section{The Handout}

The handout for the assignment may be couched in terms of Stephen Covey's book of Seven Habits of Highly Effective People. The second chapter in Covey's book is titled "Begin with the End in Mind". The opening section of your handout can make the point that if you can see the "end" - your exam 2 score then it is just a matter of putting an action plan together to get you there. Students may have talked about Covey in their management class or heard of the popular book from the media.

The second section of the handout can discuss how students develop an action plan for your next exam. This process includes having the students think about how they prepared for the first exam. Next the students need to think about why they missed the questions they did on their first exam. The students will be helped here by many of the elements of the first exam debriefing described above. To create a sense of urgency, it is helpful to describe the action plan as "what are you going to start doing today that will make your second exam score higher." Emphasis should be placed on encouraging students to develop realistic and specific ideas.

The rest of the assignment handout is dedicated to the specifics of the paper. First, students are informed that they can earn up to 10 points (on this required assignment) for a well developed, error free, and visually appealing one-page paper. If their paper is one of the top ten (top ten or twenty percent can work for smaller classes) papers it will be posted (without their name) on the course website and receive an additional five bonus points. Second, specific instructions are given to save their paper in Word and how to use the course website to submit their paper. This may be helpful for the new or non-traditional student not familiar with a course management system.The last comments on the handout are some encouraging words about showing some of their best ideas and work and how we can all benefit from the collective ideas of the class.

Students will benefit if you give them a week to do this assignment. Some students may want to further review their exam or talk with the instructor about what to do for the project. For the students who miss the class when the project was assigned, they can still have an opportunity to do the assignment. 


\section{COSTS}

For the instructor, the time and effort necessary for this assignment is minimal. Since the papers are only one page long and many of them use bullets they can be read quite quickly. Since papers are submitted electronically it is very easy to access the paper and scroll through them. Since this is a developmental assignment most of the papers will probably receive the ten points if they have made a legitimate effort and the paper is near error-free. Recall the additional five bonus points will be given to the top ten papers submitted. Reading papers with this in mind, one to two minutes per paper can be a small investment of time for the benefit of the student.

There may be a rare exception of a paper on which you may have to make a comment. Since the students saved their file in order to send it to your drop-box, all they need to know is their score on the assignment. You can post their score on the course website's on-line grade book or the drop box has a feature that you can type in a score and return it to them for very quick feedback. Additional time will be needed to save the top ten papers files (2 character file names may work well here like T1, T2) and posting them to the course website content area.

\section{BENEFITS}

One of the major benefits of this assignment is that it is structured in a way that students take ownership of their performance on exams. This happens after the student has attended the class following the exam and has learned the correct answers to the test and whether those test questions came from the book, notes, homework, or class discussion or some combination of the above. When students are left with that information they are required to see what went wrong and what they should do to fix it. The process of having the student formally address these issues and develop an action plan provides a good opportunity to communicate the "ownership" of their action plan.

The students' communication skills can be enhanced in this process. Since the assignment rewards students with bonus points for the best papers, students can focus on developing an error-free paper that presents their action plan in a way that will be visually appealing to their readers. Since the papers are posted anonymously, the students can feel safe in knowing that no one will know their identity unless they release it. It is also gratifying for the students who get the bonus points to know that their paper was one of the best in the class. The feedback students receive from reading the top ten papers that were posted to the course website provides them some feedback and ideas for preparing reports in the future.

Technology can be very helpful in making this assignment easier and more rewarding than papers that are submitted manually. The electronic submission allows you to have a deadline at midnight (which can be helpful to our students who get a late start on things). The drop-box format allows the students to get used to saving their files and sending attachments. At the same time, the drop box allows a great way to grade and return the assignment, while more importantly, the ability to save student papers and post them to the course website. This provides all students the enriching experience of seeing a well-done comparison paper and indirectly getting feedback on their own paper.

Some of the student papers submitted could provide the instructor a perspective of their students that is not typically received from traditional homework assignments. The instructor will be afforded a rare glimpse into the lives of their students and, in most cases, their tremendous desire to provide high quality performance in the classroom which is not always indicated by a test score.

\section{STUDENT FEEDBACK}

Students in an undergraduate individual tax class were provided a questionnaire after they had designed their "exam 2 strategy" and had taken the second exam. In most cases a five-point scale was provided for the students to respond to questions about their "exam 2 strategy." The results of the survey are illustrated in Appendix C and highlighted below.

- $\quad$ Over $61 \%$ of the students responded that the process of diagnosing their first exam and setting an action plan for their second exam was somewhat helpful. 
- $\quad$ More than 31\% of the students responded that they developed new ideas and strategies for taking their next exam.

- $\quad$ Over $68 \%$ of students indicated the ideas presented in the Top Ten Exam 2 Strategy Papers posted on the D2L website were very helpful or somewhat helpful.

- $\quad$ More than $60 \%$ of the students responded that they were able to implement more than $70 \%$ of their "exam 2 strategy" on their second tax exam.

- $\quad$ Over $76 \%$ of the students suggested that the next tax class would benefit from doing an "exam 2 strategy paper.”

- $\quad$ Over $43 \%$ of the students responded definitely yes or probably yes when asked if they would use the "exam 2 strategy" in other courses.

\section{CONCLUSION}

This paper presented a method to provide students a structure to improve their second exam score. The student action plan developed from the "Exam 2 Strategy" assignment takes little class time to assign and a small investment of time to assess and provide feedback.

Over a majority of students surveyed found the process of diagnosing their first exam and setting an action plan for the second exam to be helpful. They also found it helpful to view the Top Ten Exam 2 Strategy Papers that were posted on the D2L website. These students recommended that the next class would benefit from doing and "exam 2 strategy paper." Many students found that this process helped them develop new ideas and strategies for taking their second exam and plan to use the process in other courses.

When students are provided an opportunity to "actively wrestle" with their first exam score they can begin to use problem-solving skills to develop a plan for their second exam. They assess their first exam performance and creatively think of a plan of action to reach their own goal of achievement on the second exam. Written communication skills are important to articulate their plans to prepare for Exam 2. Use of the course technology website to view the top papers in the class provides peer-related, realistic, and relevant feedback. A limited amount of the instructor's time provides a project with both short-term and long-term benefit.

\section{REFERENCES}

1. Albrecht, W. S. and Sack, R. J., (2000). Accounting Education: Charting the Course through a Perilous Future. Accounting Education Series (American Accounting Association), Vol. 16. American Accounting Association (AAA).

2. American Institute of Certified Public Accountants (1999). The AICPA Core Competency Framework for Entry into the Accounting Profession, New York: AICPA.

3. Committee on the Future Structure, Content, and Scope of Accounting Education (The Bedford Committee). (1986). Future Accounting Education: Preparing for the Expanding Profession. Issues in Accounting Education, 1(1), 160-195.

4. Cunningham, B.M., (1999). Energizing your teaching: A view from deep in the trenches. Issues in Accounting Education, 14(2), 307-322.

5. Institute of Management Accountants. (1994). What Corporate America Wants in Entry-Level Accountants. Montvale, NJ:IMA.

6. Perspectives on Education: Capabilities for Success in the Accounting Profession. 1989. Arthur Andersen \& Co., Arthur Young, Coopers \& Lybrand, Deloitte Haskins \& Sells, Ernst \& Whinney, Peat Marwick Main \& Co., Price Waterhouse, and Touche Ross (The Big Eight). New York, NY. 


\section{APPENDIX A \\ Exam 2 Strategy Paper Handout \\ Exam 2 Strategy Paper \\ Due Thursday, February 26, 2006; 5:00 pm (D2L Dropbox only)}

Stephen R. Covey, author and management guru wrote a very successful book called the Seven Habits of Highly Effective People. His second chapter is called "Begin with the End in Mind". In this chapter, he makes the case that if you can see your desired end result, then being effective is putting the steps together to reach your desired end result. Now that you have had a month of Tax I, and your first assessment, you have a great opportunity to do exactly what Covey has suggested.

This assignment is your "road map" to be effective on your second exam-Exam 2 Strategy. The first step is to think about how you prepared for your first exam. Consider the questions that proved challenging on the exam. Ask yourself why you missed each question. Then develop an action plan of what you are going to start doing today that will make your second exam score higher.

Points: Up to 10 points for well developed, error free, visually appealing paper. This is a required assignment.

Bonus Points: In addition to the 10 points, the top ten papers will receive 5 bonus points and be displayed on the D2L site (without your name).

Instructions to Submit Paper Electronically: Type the maximum one-page paper in Word. Save it. Go to the D2L website. Click on your Tax I Course. Click on the Dropbox. Click on Exam 2 Strategy. Click on Browse button and select the file your paper is in. Click on the upload button. Papers will only be accepted in the Dropbox.

Let's see some of your best ideas and work. We can all benefit from the collective ideas of the class.

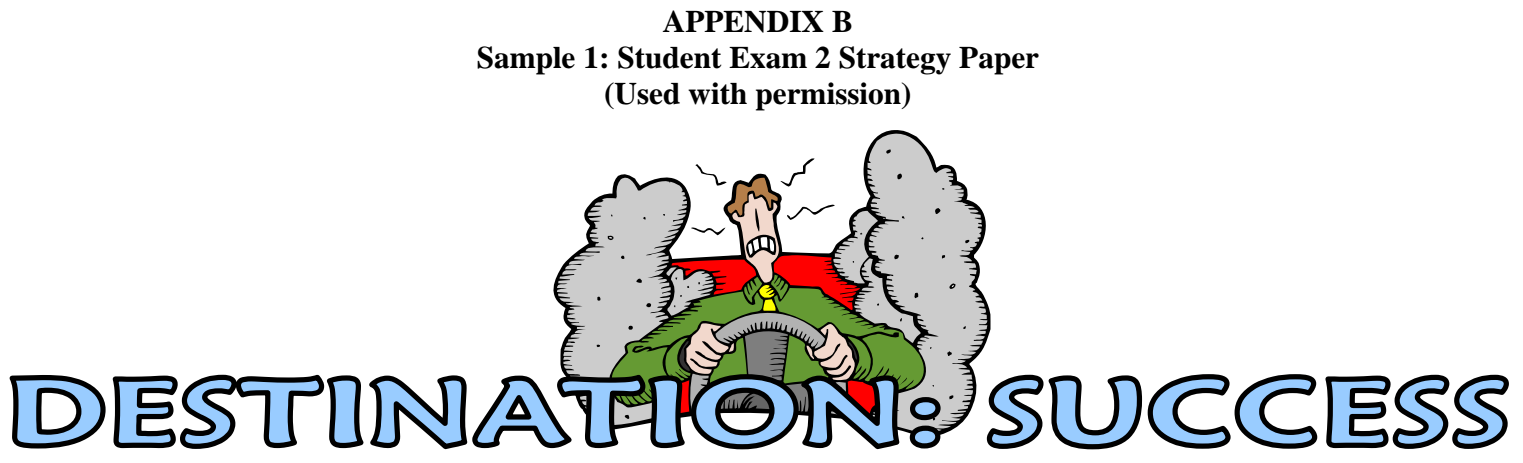

- $\quad$ Before beginning, give yourself a tune-up to make sure you have the basics down from the last exam.

- $\quad$ Keep your driving at a steady pace, so you don't have to speed study at the last minute.

- $\quad$ Don't just read the manual; understand it.

- $\quad$ If your car is making a funny noise, admit you may need help and go see a mechanic to solve the problem. (AKA: ask for help when you need it)

- $\quad$ Pay attention to the man giving directions and compare it with what you've already learned. (AKA: Listen to the professor)

- $\quad$ Before you reach your final stop, you should know your way around without a map. (AKA: you don't need to use the book to answer the questions)

- It's hard to remember directions when you don't write them down. (AKA: Don't be stupid-no one can remember all this stuff without notes)

- $\quad$ Try to get excited about the places you're going

- $\quad$ Sometimes it takes a few wrong turns to get to where you're heading. There's nothing wrong with that, unless you don't learn from the mistakes.

- $\quad$ You can't do anything until you get in the car-SO GET GOING ALREADY! 


\section{Sample 2: Student Exam 2 Strategy Paper (Used with permission)}

It is common verse that "Hindsight is 20/20". While this slogan may be slightly overused, it is also slightly under-rated. Many view past events as an irreconcilable chapter in their book of experiences that is never read, much less studied. However, to the select few who take the time to review past discretions/mistakes, they find an inherent wealth of knowledge hidden behind the rough outer crust of their experiences. My experience with the last Tax exam caused me to see a plethora of transactions that I did both correct and incorrect.

Due to the nature of an open book exam, an individual has a tendency to prepare themselves slightly less than they may for one that is not (because of the fact that they have the ability to reference unknown answers). While I knew that this option was both helpful and treacherous, I believe that I did not properly prepare myself. During the test it was apparent that minutes passed like seconds when you found yourself searching for a specific answer to a question. To properly have prepared myself, I should have focused less on learning reference points in the book, and more about the pure mastery of the material (to the point of not needing the book's assistance). The book is a very effective tool that can certainly affect your grade in a positive manner when used properly. It should only be used to reference specific and exact material for no more than a handful of questions (this is all time that will be available to you when referencing specific questions on a test).

I found the nature of the questions on the test to be very indicative of homework and review problems, but did not answer them with the confidence that I answered assignments with. I believe that this failure was due to the fact that I neglected the basic fundamentals of each question by not properly addressing all points of the problem. During homework problems you become very comfortable with the points that need to be addressed and work systematically through them. During the test I neglected to cover the same points, run the same tests, and recall specific information necessary to the problem. I believe that it is important, no matter where the problem, to gather the known facts, recall any information related to the question, and asses whether or not this information is pertinent to the question. By failing to do this on some test questions, simple mistakes were made and valuable points were lost.

Lastly, I believe that is important to know the information even better than what you think is necessary to be successful on an exam. To know how to do a certain type of problem is not nearly enough. Instead, one should strive to know all aspects of a problem so that they may pick up on it in the beginning, middle, or end and work it backwards if necessary. By being able to do this (and testing your own ability in practice to do this) you will be assured that you are extremely comfortable with a question and will not fall subject to the negative effects of test anxiety.

After the review of my past test preparation practices, I had personally decided to make a number of alternations that I am confident will lead to indubitable success. First, I plan to prepare for an exam that does not allow the assistance of a textbook. The information should be clear enough in my mind that I can readily recall it and work with it from any point in the problem. It would be foolish to turn my back on the resourcefulness of the book, and I will therefore still create quick reference points for complicated material that can assist me on specific questions but will certainly not rely upon the book for theory related questions (these are the most time expensive questions when searching and are not affordable on a test). I will also make certain to specifically review and master homework questions, classroom examples, and class handouts (knowing that the bulk of the test material will be based upon these items).

I believe that it is most important to remember that nothing worthwhile has ever come easily in life. Education is a continual process that requires dedication, a tolerance for pain, and a bulldozer when necessary. It is not a question of whether you will fall or not (because you will), but rather how quickly you realize your mistake and correct it. In accompaniment with Stephen Covey's view for this assignment I am also encouraged by a quote from a great poet in the book, "Think and Grow Rich" by Napoleon Hill. "I had bargained with life for a penny, and life would pay no more. However I begged at evening when I counted my scanty store. For life is just an employer, he gives you what you ask, but once you have set the wages, you must bear the task. I worked for a menial's hire, only to learn dismayed, that any wage I had asked of life- life would have willingly paid." 


\section{Sample 3: Student Exam 2 Strategy Paper}

(Used with permission)

Intermediate I Accounting- Study Plan

I. Ongoing Preparation Four Weeks Between Exams (KEY IS DEVELOPING BASIC KNOWLEDGE)

A. Constants from Exam I

1. Read chapter before class to attain comprehension of basic material. Don’t try and memorize, just gain familiarity with all relevant topics.

2. Take sufficient class notes and reinforce main points made during class two to three hours after class is completed.

3. Do homework one week in advance of due date in order to have ample time to seek answers to questions on material presented within the exercises.

B. Differences in Study Habits

1. Go in depth with class notes by reading corresponding sections in book in order to develop and understand key points better.

2. Highlight especially difficult homework or class problems to go over again and if necessary find additional problems to reinforce complex or confusing topics because they are the ones most likely to present difficulty on the exam.

3. Take two more hours to study for quizzes (treat like tests) and go over all notes including notes from previous class. This will help simulate exam preparation.

\section{One To Two Weeks Before Exam (KEY IS FINDING AND FIXING SOURCES OF CONFUSION)}

A. Constants from Exam I

1. When homework is handed back, pinpoint mistakes and seek additional help or try similar problems in order to make sure the error(s) is rectified.

2. Read class notes with specific focus on topics that are likely be emphasized on exam.

3. Draw up detailed outline each chapter and pick out weak points to further study.

B. Differences from Exam I

1. Clarity- Make sure each term and topic relevant to the exam is becoming clear and fully developed down to the most minute detail.

2. Plan out schedule for exam week and ensure that proper preparation time will not be interfered with by work or other obligations.

3. Develop self-test by pulling terms and formulas out of notes and try to fill out blank formulas or recreate definitions without outside help.

\section{One To Four Days Before Exam (KEY IS DEVELOPING PLAN AND MENTALLY PREPARING)}

A. Constants from Exam I

1. Go over test breakdown one more time and do a quick review of chapters based solely on their weight on the test.

2. Try any new book problems and make up multiple choice questions to make sure I have looked at all topics from more than one angle or circumstance.

3. Seek additional help for any points of confusion that cannot be remedied through the text.

B. Differences from Exam I

1. The night before the exam go over rules and be cognizant of tips that have been gleaned through four weeks of extensive preparation. (There are many small details that are easy to miss in a problem and can throw off the final answer) 
2. Construct a plan of attack by deciding which problems to do first based on confidence in preparation and complexity of material. (difficult problemsdone last)

3. Get at least eight hours of sleep before test and eat a healthy breakfast.

4. Relax three hours before test and do no look at accounting related work to ensure mental freshness.

\section{Sample 4: Student Exam 2 Strategy Paper (Used with permission)}

\section{Comprehensive Study Plan}

The previous accounting exam I was left unsatisfied. I got a score of 95, which I think was an AB score, but I'm accustomed to doing better. Part of doing well on exams is getting accustomed to the style and presentation of the exam. Every professor is different, and the same can be said for these accounting exams. But the majority of doing well on exams stems from being mentally prepared. With that said, here is a view of how I am going to study for future accounting exams.

One thing that I have always done, and will continue to do is to devote a significant amount of time the night before the exam, and do a complete comprehensive review of the material that will be on the test. Going through the online review notes, reworking problems then cross referencing them with ones I've already to completed to see if I understand what I am doing, and possibly just rereading all the chapters involved. Also reviewing quizzes from material on that will be on the exam are very important. I know that I learn and retain the most when I see what I have done wrong and have time to learn from it. What I am thankful for is that in this class you let us keep our quizzes. You breeze over them in class, and I can fix what I've done wrong, but in order to really learn I need look the quiz over on my own time to fully comprehend my mistake. I hate Cost Management because Sager doesn't let us keep our quizzes. He may breeze over them in class as well and give us the right answers, but then we have to give them back to him before class is over anyway so I don't have time to learn anything from them. These have all been staples in my routine, pre-exam day regimen, and are a key to my exam success.

With the way that these accounting exams are scheduled, (4:00 p.m. in the afternoon on Mondays) it would be nice to come into the exam without any pressure. Last semester for Accounting 244, Exams were scheduled similarly, but I knew the exam schedule before I registered for classes that semester so I made sure not to put any classes right in front of the exam times. That way I could get a good last final review in before the exam and feel confident in what I was doing. That would also be an important part of my study plan now, but unfortunately, I didn't have the exam schedule when I registered for classes, (as you've apologized for already) and unluckily I have a chemistry lab that runs up until 3:55 p.m. every Monday. My ideal study plan would have at least a one-hour study window before the exam, but instead I have the added stress of just trying to make it to the exam on time. But I suppose that's the way it goes.

The problem with my study habits is that I don't review sufficiently while we are still learning the chapters. Too many times do I not start to get down to business with the material until a few days before the exam. My problem is that for my whole academic career I've been able to skate by getting mostly A's with my laziness. What causes this problem needs to be addressed. Subconsciously, I look at this accounting class as "just another class that I have to pass," when in reality my perception should be "this is my future career I'm learning, so it’s to my benefit to learn, love, and retain this information.” Granted, I enjoy accounting, but it is hard for me to have a diehard passion for it. Maybe my perception will change down the road a few semesters, but that's not the topic of discussion for this paper.

My study habits need to change. Devoting a large portion of my time the day before the exam will always be a part of my study plan because I believe that it has contributed to a large part of my academic success. However, where I will make a change is during the time while learning the material. Reviewing the material thoroughly after each class period will become a ritual, as well as doing problems in the book that aren't assigned (ones that I have check figures for). This should ease the learning curve that I have to do on the night before the exam, and should improve my confidence and ability in preparing for exams. 


\section{APPENDIX C \\ Exam 2 Strategy Questionnaire (N=48)}

1. Was the Exam 2 Strategy process of diagnosing your first exam and setting an action plan for the second exam helpful to you?

\begin{tabular}{|c|c|c|c|c|c|}
\hline & $\begin{array}{l}\text { Very } \\
\text { Helpful }\end{array}$ & $\begin{array}{l}\text { Somewhat } \\
\text { Helpful }\end{array}$ & Undecided & $\begin{array}{l}\text { Not } \\
\text { Helpful }\end{array}$ & $\begin{array}{l}\text { Waste } \\
\text { of Time }\end{array}$ \\
\hline count & $\overline{0}$ & $\overline{29}$ & 8 & $\overline{7}$ & 3 \\
\hline percent & $0 \%$ & $61.7 \%$ & $17.0 \%$ & $14.9 \%$ & $6.4 \%$ \\
\hline
\end{tabular}

2. Did preparing an Exam 2 Strategy Paper develop ideas and strategies that you would not have developed if you had not done an Exam 2 Strategy Paper?

$\begin{array}{lll} & \underline{\text { Yes }} & \text { No } \\ \text { count } & 18 & 30 \\ \text { percent } & 37.5 \% & 62.5 \%\end{array}$

3. How would you characterize the ideas presented in the Top Ten Exam 2 Strategy Papers that were posted on the D2L website?

$\begin{array}{llllll} & \begin{array}{l}\text { Very } \\ \text { Helpful }\end{array} & \begin{array}{l}\text { Somewhat } \\ \text { Helpful }\end{array} & \underline{\text { Undecided }} & \text { Not } & \text { Did Not } \\ \text { count } & 4 & 29 & 3 & 4 & \underline{\text { View }} \\ \text { percent } & 8.3 \% & 60.4 \% & 6.3 \% & 8.3 \% & 16.7 \%\end{array}$

4. What percent of your Exam 2 Strategy were you able to implement in preparing for your second tax exam?

\begin{tabular}{|c|c|c|c|c|c|}
\hline & $\begin{array}{l}\text { Did Not } \\
90 \%-100 \%\end{array}$ & $80 \%-89 \%$ & $70 \%-79 \%$ & $<70 \%$ & Use \\
\hline count & 6 & 914 & 14 & 5 & \\
\hline percent & $12.5 \%$ & $18.7 \%$ & $29.2 \%$ & $29.2 \%$ & $10.4 \%$ \\
\hline
\end{tabular}

5. Based on your experience would the next tax class benefit from doing an Exam 2 Strategy Paper?

$\begin{array}{lll} & \frac{\text { Yes }}{35} & \text { No } \\ \text { count } & 36.1 \% & 11 \\ \text { percent } & 76.9 \%\end{array}$

6. Will you use the exam strategy process you learned in this class in your other courses at UW-Whitewater?

\begin{tabular}{|c|c|c|c|c|c|}
\hline & Definitely & Probably & & Probably & Definitely \\
\hline & $\underline{\text { Yes }}$ & Yes & Undecided & Not & Not \\
\hline count & $\overline{3}$ & $\overline{18}$ & 7 & 14 & 6 \\
\hline percent & $6.2 \%$ & $37.5 \%$ & $14.6 \%$ & $29.2 \%$ & $12.5 \%$ \\
\hline
\end{tabular}


NOTES 